\title{
Overcoming Gender Bias in STEM: The Effect of Adding the Arts (STEAM)
}

\author{
Clara Wajngurt, PhD \\ Professor, Mathematics and Computer Sciences Department \\ City University of New York \\ Pessy J. Sloan, PhD \\ Assistant Professor, Education Department \\ Daemen College
}

\begin{abstract}
This study investigated female students who attended a STEM course with the Arts (STEAM) in comparison to a traditional STEM course and the impact it had on desire to pursue a STEM degree. An independent-samples t-test was conducted to compare female to male students' interest in pursuing STEM degrees. In addition, follow up data for registration in STEM subjects was calculated. The participants $(N=58)$ consisted of college students (35 female students and 23 male students) attending a postsecondary institution in the northeastern United States. The study found significant differences $(p<.05)$ between the groups and a larger percentage of female students from the STEAM course than from the traditional STEM course enrolled in another STEM course at follow up. These results support the positive relationship between female students attending a STEAM course and desire to pursue a STEM degree. The implications and results of adding interdisciplinary elements to traditional STEM courses for female students are discussed.
\end{abstract}

Science. Technology. Engineering. Mathematics. Commonly known as "STEM," these are the fields that have substantial influence on global progress, innovation, and economic success, as well as the potential to ameliorate many of the world's most urgent problems, such as poverty, environmental damage, clean water, food insecurity, renewable energy, and more (Clynes, 2016). In recent years, it has become painfully clear that America is not producing enough experts in STEM fields (McClarty, 2015). Furthermore, within the pool of STEM workers, there is a marked gender disparity; with a few exceptions, women are significantly underrepresented in most areas of STEM (U.S. Bureau of Labor Statistics [BLS], 2015).

One strategy that has been proposed to attract more women to STEM fields is a more interdisciplinary approach to STEM education. STEAM (STEM + the Arts) is an educational approach to learning that uses Science, Technology, Engineering, the Arts and Mathematics as access points for guiding student inquiry, dialogue, and critical thinking. It is also used to broaden interest in STEM fields (Sochacka, Guyotte, \& Walther, 2016). Adding the Arts to the traditional STEM curriculum (thus creating "STEAM") allows for a more multi-faceted and engaging approach to STEM (Boy, 2013) and may catch the interest of students previously uninterested in STEM.

Since men outnumber women by 3 to 1 overall in STEM fields (U.S. Bureau of Labor Statistics [BLS], 2015) and only 35.2\% of chemists are women (The National Girls Collaborative Project, 2016), it is important to concentrate on increasing women in these particular subject areas. Chemistry is a fundamental discipline that accounts for life at the molecular level. We use chemicals daily without even realizing it. All matter is made of chemicals, so the significance of chemistry is that it's the study of everything (Helmenstine, 2018). Therefore, the current study evaluated the impact of a "Chemistry with the Arts" course (which incorporated the application and utilization 
of relationships between chemistry with everyday life and the arts) on female students' later pursuit of additional STEM courses in a community college compared to female students who attended a traditional Chemistry course.

\section{Need for Women in STEM}

\section{Background}

In addition to the simple fact that the United States needs to nurture and empower people of all genders to pursue STEM in order to literally make the world a better place, women who pursue STEM bring unique talents, skills, and perspectives to their fields. A lack of female input in critical STEM areas at best slows innovation and global progress; at worst it can have life-threatening implications. According to Hill, Corbett, and St. Rose (2010), "Engineers design many of the things we use dailybuildings, bridges, computers, cars, wheelchairs, and X-ray machines. When women are not involved in the design of these products, needs and desires unique to women may be overlooked" (p.3). For example, the original automobile airbags were designed by men for the adult male body, and some deaths of women and children resulted from the deployment of these airbags, which might have been avoided had there been women engineers involved in the design (Margolis \& Fisher, 2003, pp. 2-3).

STEM not only benefits global society and American economic competitiveness but can also have tangible economic benefits for women. It has been well documented that on average, women earn less than men in all career areas in the United States. In non-STEM careers, the overall wage gap is 21\% (Beede et al., 2011). However, in STEM careers the wage gap is one-third lower: 14\% (Beede et al., 2011). In addition to the smaller gender wage gap, there is a larger STEM earnings premium for women because women in STEM careers earn 33\% more than comparable women in non-STEM careers, while the STEM premium for men is only 25\% (Beede et al., 2011). Despite these statistics, the majority of women continue to major in female-dominated subjects, such as education, health, and psychology, even though they tend to earn less than they would in male-dominated majors such as engineering, mathematics and physical sciences (Goldberg Dey \& Hill, 2007). If women with a natural inclination and desire toward STEM are encouraged to pursue those career areas rather than nonSTEM careers, they will be better compensated financially over the course of their professional life. For men and women, STEM-related positions are expected to grow by $17 \%$ over the course of 10 years while non-STEM jobs have been increasing only by $9.8 \%$; furthermore, workers in STEM careers earn an average of $26 \%$ more than those in non-STEM fields (Langdon, McKittrick, Beede, Khan \& Doms, 2011).

\section{Women in the Workforce and Academia}

According to the $12^{\text {th }}$ US Census, in 1900 women made up about $18 \%$ of the "gainfully employed" labor force (Abbott \& Breckinridge, 1906, p. 18). This increased to around 30\% in 1950 (U.S. President's Commission on the Status of Women [PCSW], 1963, p.28). As of 2015, nearly $47 \%$ of the American workforce was female, and women made up 52\% of management and professional occupations ( $\mathrm{O}^{\prime}$ Farrell, 2015).

Women have made substantial gains in their participation in law, medicine and business. The American Bar Association (ABA) has documented that female law 
students now make up almost half of law students attending accredited law schools (ABA, 2017). According to the Association of American Medical Colleges (AAMC), more women than in the past choose occupations in medicine, and in 2016 there were more female applicants to medical schools than males (Bergen, 2016). The Graduate Management Admission Council (GMAC) reports growing numbers of applications of full-time two-year MBA programs for women in 2016 (GMAC, 2015). Women now make up about $40 \%$ of students at full time MBA programs (Moran, 2015).

In recent decades, improvements have been made in the numbers of women in STEM professions; however, they are still underrepresented in many STEM fields. Men outnumber women by 3 to 1 overall in STEM fields, particularly engineering and physics (U.S. Bureau of Labor Statistics [BLS], 2015). Although women comprise nearly half $(47 \%)$ of the total U.S. college-educated workforce, they make up only $24 \%$ of the science and engineering workforce (Beede et al., 2011). The National Girls Collaborative Project (2016) reports that female scientists and engineers tend to concentrate in different occupations than men, with fairly large proportions of women in the social sciences (62\%) and biological, agricultural, and environmental life sciences $(48 \%)$ and relatively low proportions in engineering $(15 \%)$ and computer and mathematical sciences (25\%). The engineering, computer, and math statistics can be further broken down to a selection of specific STEM careers to show that women comprise $35 \%$ of chemists; $11 \%$ of physicists and astronomers; $34 \%$ of environmental engineers; $23 \%$ of chemical engineers; $18 \%$ of civil, architectural and sanitary engineers; $17 \%$ of industrial engineers; $11 \%$ of electrical and computer hardware engineers; and $8 \%$ of mechanical engineers (NGCP, 2016).

In many academic fields, women today earn the majority of college degrees in America. They outnumber men in obtaining associates, bachelors, masters, and doctoral degrees (National Center for Education Statistics [NCES], 2017). In 2013 women earned $57.3 \%$ of bachelor's degrees in all fields and $50.3 \%$ of science and engineering bachelor's degrees. However, women's participation in science and engineering at the undergraduate level significantly differs by specific field of study. While women receive over half of bachelor's degrees awarded in the biological sciences, they receive far fewer in the computer sciences $(17.9 \%)$, engineering $(19.3 \%)$, physical sciences (39\%) and mathematics (43.1\%) (NGCP, 2016). At the PhD level, the proportion of women in the biosciences and social sciences has increased (to $40 \%$ female), and women are now overrepresented in psychology (78\% female). However, men still vastly outnumber women in computer science (75\% male) and engineering (77\% male) (Noonan, 2017; National Science Foundation [NSF], 2016).

In the population as a whole, women hold almost as many undergraduate degrees as men; however, women make up a much lower number of STEM degree holders (about 30\%). Women are disproportionately underrepresented among degree holders in all STEM fields, especially engineering (Noonan, 2017). Furthermore, women who have a STEM degree are more likely to work in education or healthcare than pursue a STEM career, unlike men with STEM degrees (Noonan, 2017). Despite a number of initiatives intended to increase the number of women in STEM, from 2000 to 2011 the number of science and engineering bachelor's degrees awarded to women remained level or even declined in computer sciences, mathematics, physics, engineering, and economics (National Science Board [NSB], 2016).

InSight: A Journal of Scholarly Teaching 
Overall, while significant increases have been made in women's choices to pursue STEM majors in post-secondary schooling and women's participation in the STEM workforce, the nature of women's progress in STEM is complex. Unpacking the statistics shows that the increases are very unevenly distributed across different STEM fields, possibly indicating that more barriers have been removed or overcome in some fields, but not in others.

\section{Barriers to Women's Pursuit of STEM}

Stereotyped school subjects. Historically, women have been encouraged to pursue English, reading and the arts, and at times have even been actively dissuaded from pursuing sciences and mathematics (Huston, 1983). This was at least partly because of stereotypes about females not having naturally "mathematical" or "scientific" minds. Subject stereotyping negatively affects women's performance (Marx, Brown, \& Steele, 1999). The idea that men innately possess more aptitude than women in mathematically dominant fields, whereas women naturally excel in subjects using language skills, is damaging to women because it shortchanges the true diversity of their abilities (Hill et al., 2010). Lingering gender stereotypes remain in school subjects to this day. There are many forms of bias in subject choices, and schools often tend to follow traditional views of certain subjects being "feminine" and others being "masculine." When high school subjects were examined, physics, math and economics indicated a male bias; while biology, English and psychology indicated a female bias (Institute of Physics [IOP], 2013). Unfortunately, subject bias affects women's choices in college when deciding on a major (Marx \& Roman, 2002). Women are less likely to pursue STEM fields. In addition, female students who start their bachelor's program with the intention of pursuing a STEM degree are more likely to switch to a non-STEM major than their male peers (Chen, 2013).

Helping fields. Morgan, Isaac, and Sansone (2001) found that students viewed STEM careers as less connected to humanitarian ideals and interpersonal goals than non-STEM careers. When choosing a career, women tend to gravitate toward "helping" professions and interpersonal goals (Lackland \& De Lisi, 2001); therefore, the perception that STEM fields are not associated with these goals may be one reason that women tend to steer away from STEM subjects.

Most career fields in the United States are male dominated, other than education and healthcare (Goldberg Dey \& Hill, 2007, p.22). Even though only 37\% of physicians and surgeons are women, about $74 \%$ of all technical (i.e., STEM-focused) healthcare practitioners are women. Similarly, about $74 \%$ of all workers in educational roles are women. Education and healthcare careers are considered "helping" fields. Not surprisingly, these helping fields encompass a larger proportion of full-time working women than men. Furthermore, twice as many women than men $(22 \%$ of women vs. $11 \%$ of men) pursue jobs in nonprofit companies (Goldberg Dey \& Hill, 2007, p.23). This indicates that more women focus their talents and ambitions towards careers that directly help others, either from natural inclination or cultural socialization and expectations of females.

Lack of female role models in STEM. Research has shown that women's pursuit of a STEM major is influenced by female role models and mentors (Goodman 
\& Damour, 2011). When female students have female professors, some studies have discovered that "their stereotypes can be not only reduced, but inverted" (Young, Rudman, Buettner \& McLean, 2013, p. 289). Increasing the number of female faculty members teaching STEM courses can have a strong encouraging effect on the pursuit of STEM careers by women, while also decreasing biases and negative stereotypes in the STEM fields (Frost, 2017).

Connecting secondary school students to STEM activities and role models is important to the development of STEM interest and career expectations. Girls are rarely exposed to female role models in STEM fields, which adds to the stereotype that the STEM professions are typically male (Marra, Peterson, \& Britsch, 2008).

For all students, perhaps an inability to identify with STEM concepts is related to a lack of personal relationships with other STEM students or STEM professionals in the classroom. However, studies demonstrate that STEM initiatives for females can strengthen girls' identification with STEM by developing positive attitudes, interest and self-efficacy in STEM fields (Marra et al., 2008).

Educational outreach initiatives show that female students from diverse groups, including those of low socioeconomic status, need STEM role models who are inspirational and who can relate to their experience (Marra et al., 2008). Since recent research shows that women rely on and benefit from same-sex role models more than men do, an increased presence of female faculty and staff can have a positive impact on the educational attainment of female students (Frost, 2017). Therefore, female role models and mentors in college can help female students persevere in STEM majors (Goodman \& Damour, 2011).

STEM pipeline. It would be a mistake to underestimate the influence of elementary and secondary education on a student's interest in pursuing STEM in postsecondary schooling and beyond. Each step is necessary, leading to the next stage and impacting the success of the final accomplishment of pursuing a career in STEM.

The STEM pipeline is the phrase used to describe STEM education throughout schooling levels and eventually culminating in the labor force. The development of a new scientist begins quite early and can only be accomplished through a series of steps. It starts with primary and secondary school, where students have to acquire both the skills and the interest in STEM fields to be successful in postsecondary studies. It continues grade by grade as students continue to acquire the skills and interests that might shape their decision as to whether or not to study STEM fields after secondary school (Bettinger, 2010, p. 72).

Exposure to STEM has to begin in kindergarten (Duncan et al., 2007), especially for girls, before they internalize gender stereotypes and cultural beliefs about their ability and competence to achieve in STEM. The United States currently has a leaky pipeline where STEM is introduced too late, so that women are not pursuing STEM fields in similar proportions to men.

\section{Interdisciplinary Subjects and STEAM}

STEM is essential, but equally important are the arts. STEM and the arts are not mutually exclusive. Scientific culture and technology have nurtured artistic innovations in many areas (and engendered new artistic fields such as digital design); 
similarly, the arts have influenced STEM developments and discoveries (Herrmann et al., 2016). Many of the most innovative thinkers in STEM fields are highly creative people with an interdisciplinary approach to life; they are polymaths who are intensely influenced by music, the arts and other creative pursuits (Caper, 1996; Dail, 2013; Eger, 2013; Root-Bernstein, 2003). Research has found that Nobel prize winners are significantly more likely to pursue artistic hobbies, engage in a craft, or play a musical instrument than the general public (Root-Bernstein et al., 2008). For centuries, STEM and the arts have fed off one another in a mutualistic fashion. As demonstrated during the Renaissance Era, Leonardo da Vinci, who is best known as an artist, was also a scientist and inventor.

According to Catterall (2002), innovative thought in STEM fields is coming to depend more and more on eliminating the traditional separation between artistic disciplines, which are seen as "creative," and STEM disciplines, which are seen as more rigid, logical, or mathematical. Innovation will be hindered if schools continue to teach isolated disciplines based on simple reductionism; the arts should be incorporated into STEM to promote creativity together with reason and logic (Boy, 2013). This incorporation (STEAM) will help produce a multi-literate citizenry and workforce as the $21^{\text {st }}$ century marches on (Taylor, 2016). Students who are exposed to the integration

STEM traditionally focuses on convergent of arts and sciences develop a skills whereas art traditionally focuses on divergent skills; having a workforce with exposure and capabilities in both types of skills is beneficial for America's competitiveness and global progress.

unique skill set (Land, 2013). STEM traditionally focuses on convergent skills whereas art traditionally focuses on divergent skills; having a workforce with exposure and capabilities in both types of skills is beneficial for America's competitiveness and global progress (Land, 2013). This means, Ball (2004) explains, "It will seem perhaps to be a strange notion, to non-chemists, that chemistry has an aesthetic. But it does. Chemists often make molecules that are admired not for their utility or ingenuity but for their artistry. These molecules are perceived to be beautiful. That is, sometimes, the sole reason for their creation" (Ball, 2004, p.185). Ball (2004) believes that chemistry itself can be artistic and beautiful.

As a result there is a movement to include art and design in STEM education that builds on existing models of the interdisciplinary curriculum (Costantino, 2017). The interdisciplinary curriculum is based on an approach that integrates two or more subject areas, like the Arts and Sciences into a more meaningful association that enhances and enriches learning within a particular subject, in this case the Sciences (You, 2017). It is thought that an effective way to learn about phenomena in the real world could use an interdisciplinary approach (You, 2017), by employing concepts that use STEAM learning. In this way, interdisciplinary learning facilitates the thinking process in the sciences by incorporating the arts through the processes of critical thinking, deductive reasoning and reasoning by analogy. This interdisciplinary learning approach for Science learning or the STEAM approach will provide a rationale for understanding the big picture of the science concept applied to the real world. Moreover the interdisciplinary STEAM approach for learning STEM subjects involves collaborative learning amongst students because such learning further creates a natural 
awareness of applying a STEM concept to the real world by using concepts in art or design. So when the original rigor of learning STEM subjects is connected to real world applications by adding artistic and design concepts, the STEM subject takes on a life of its own-called STEAM learninghelping students to better understand the STEM subject. Some universities have developed a multidisciplinary curriculum, which is a model intended to foster creative thinking by combining STEM fields with the arts and humanities (Madden et al., 2013).

Furthermore, as technology and global issues become more complex, many STEM fields are crossing boundaries and becoming more interdisciplinary with each other, which requires graduates who are capable of thinking about and working in multiple fields (Kezar \& Elrod, 2012). The next generation of creative STEM professionals will need a polymathic blend of interests and skills in creative fields and multiple STEM fields (Shneiderman, 2003). Based on the prior research regarding the benefits of having a female role model in STEM subjects and adding the arts to STEM in order to increase interdisciplinary practitioners in the STEM field, the following hypotheses were formulated.

\section{Hypotheses}

H1: A STEM class with an arts component (STEAM), when compared to a traditional STEM class without the arts, will positively affect female students' intentions to pursue STEM when compared to male students at the beginning of the semester.

$\mathbf{H}_{2}$ : Having a female STEM instructor will positively influence more women to pursue STEM subjects among students who attend a STEM with the arts class than women who attend STEM without the arts, compared to male students in the same classes.

$\mathbf{H}_{3}$ : More female students from the STEAM class will register for another STEM class over the next two semesters compared to female students from the traditional STEM (without the arts) class.

\section{Participants}

\section{Method}

The sample pool was drawn from 4 classes at a community college in the Northeastern United States, taught in the Fall 2016 and Spring 2017 semesters. Two classes were chemistry with the arts, and two were chemistry without the arts. The same female STEM instructor taught all 4 classes and was a fixed variable in order to rule out differences in teacher's personality and teaching styles.
Table 1

Chemistry with the Arts (STEAM)

Total

Fall 2016 \& Spring 2017

\begin{tabular}{ll} 
Pre-test & $(\mathrm{n}=30)$ \\
Male & $=15$ \\
Female & $=15$ \\
Post-test & $(\mathrm{n}=18)$ \\
Male & $=9$ \\
Female & $=9$ \\
\hline
\end{tabular}


Table 2

Chemistry without the Arts (Traditional STEM)

\section{Total}

Fall 2016 \& Spring 2017

\begin{tabular}{ll}
\hline Pre-test & $(\mathrm{n}=28)$ \\
Male & $=8$ \\
Female & $=20$ \\
Post-test & $(\mathrm{n}=16)$ \\
Male & $=6$ \\
Female & $=10$ \\
\hline
\end{tabular}

\section{Explanation of Terms}

STEM with the Arts (STEAM). The "Chemistry and the Arts" course offered a general background in the connections between chemistry and the arts. Topics include light absorption and reflection; the nature of color; additive and subtractive color mixing; separation of mixtures; chemical properties, synthesis and use of dyes, paints and pigments; the chemistry of

art preservation and authentication of art objects; the hazards of chemicals used by artists; the principles of photography. The laboratory component applied chemical theory and techniques to practices involved in creating works of art such as photography, painting, and textiles. Students use modern laboratory instrumentation, such as Ultraviolet-Visible (UV-Vis) Spectroscopy and chromatography to examine materials used in art. For example, the blueprint reaction method of photography (also called cyanotype, which is a photographic printing process that produces a cyan-blue print) dates back to the 1840's. The photosensitive chemicals used include some iron salts discovered by Sir John Herschel. The process of light exposure and development is similar to black and white photography, where silver halides are used as photosensitive chemicals (Karimi, Hemraj-Benny, \& Bojin, 2015, p. 71). The objective is to make chemistry vivid and easy to understand by employing concepts and methods of the physical sciences to understand the world around us.

STEM without the Arts (traditional STEM). The "Chemistry Fundamentals" course provided students with basic knowledge of modern theory of general chemistry. The course covers topics of general chemistry, including classification and properties of matter, elements and compounds, atomic theory, the periodic table, chemical composition, chemical equations, acids and bases, and chemical bonding. The laboratory experiments gave hands-on experience using principles of chemistry theory to the students. The objective was to use analytical methods to identify issues and evaluate evidence.

\section{Research Design}

This research used a quasi-experimental design. Participants were not randomly assigned because the classes used were already intact. The pre-test/post-test design was used to detect if the STEAM course taught by a female instructor had a significant effect on interest in pursuing a STEM degree among female students compared to a traditional STEM course, as measured with the pre-test/post-test survey responses.

Independent samples t-tests were used to compare pre- and post-test survey responses from the STEAM course and the traditional STEM course in order to see if there was a significant difference in male and female interest in pursuing a STEM degree at the beginning of the semester compared to the end of the semester. 
Registration data was gathered for students who participated in the STEAM course and the traditional STEM course to determine whether female students from the STEAM class registered for another STEM course. Percentages were calculated for the entire STEAM course and the traditional STEM course as well as specifically looking at gender differences.

\section{Procedure}

Four classes were used as the sample: two STEAM, (one in Fall 2016 and one in Spring 2017) and two STEM without the arts classes (one in Fall 2016 and one in Spring 2017). The participants attended a community college in the northeastern United States. All participants signed consent forms, and then completed the same survey at the beginning of the course and again at the end of the course. The survey included a Likert scaled question regarding personal interest in pursuing a STEM degree: "Strongly Agree," "Agree," "Not Sure," "Disagree," or "Strongly Disagree." As follow-up to the survey, registration data were gathered for students who attended the STEAM class and the traditional STEM class for the two semesters following the course.

\section{Data Analysis}

An independent-samples t-test was conducted to compare male and female students on the pre-test and post-test scores for the survey question about desire to pursue a STEM degree in both the STEAM class and the traditional STEM class. An example of the question on the survey administered pre and post chemistry courses were "I am likely to pursue a STEM degree." The survey questions were scored on a Likert scale, which consisted of descriptive terms including "Strongly Disagree," "Disagree," "Neutral," "Agree," and "Strongly Agree."

In order to triangulate the data with more sources of evidence, registration data was evaluated for all students taking a STEM course two semesters following the courses studied.

\section{Independent-Samples T-Tests}

\section{Results}

STEAM course pre-test. There was a significant difference in the survey scores for women's interest in pursuing a STEM degree in the beginning of semester $(\mathrm{M}=2.8$, $\mathrm{SD}=1.5)$ compared to men at the beginning of semester $(\mathrm{M}=2.2, \mathrm{SD}=.67)$ conditions; $t(16)=-1.194, p=0.028$. These results suggest that female students in the STEAM course were significantly more willing to pursue a STEM degree at the beginning of the semester than male students.

Traditional STEM pre-test. There was no significant difference in the traditional STEM course in the pre-test scores on desire to pursue a STEM degree between females $(\mathrm{M}=3.2, \mathrm{SD}=1.2)$ and males $(\mathrm{M}=2.8, \mathrm{SD}=1.5)$ conditions; $\mathrm{t}(14)=-.537$, $p=.599$. These results suggest that males and females were not significantly different in their desire to pursue a STEM course when they started the traditional STEM course. 
STEAM course post-test. There was a significant difference in the survey scores for women's interest in pursuing a STEM degree at the end of the semester $(\mathrm{M}=2.56, \mathrm{SD}=1.67)$ compared to men at the end of semester $(\mathrm{M}=1.78, \mathrm{SD}=.83)$ conditions; $\mathrm{t}(16)=-1.252, \mathrm{p}=0.032$. These results suggest that despite the scores minimally decreasing from the beginning of the semester, upon comparison of the pre-test versus post-test scores, female students in the STEAM course still wished to pursue STEM degrees significantly more than male students at the end of the semester.

Traditional STEM post-test. There was a significant difference in the post-test scores on desire to pursue a STEM degree in the traditional STEM course for females $(\mathrm{M}=3.6, \mathrm{SD}=.97)$ compared to males $(\mathrm{M}=2.3, \mathrm{SD}=1.37)$ conditions; $\mathrm{t}(14)=-2.179, \mathrm{p}=.047$. These results suggest that women were significantly more likely than men to be interested in taking another STEM course when they finished the traditional STEM course.

Follow up, registration data found that $16.7 \%$ of the students $(n=30)$ who attended the STEAM course attended another STEM course within the next two semesters, while $32.1 \%$ of the students $(n=28)$ who attended the traditional STEM course attended another STEM course within the next two semesters. Students from the traditional STEM course were nearly twice as likely to pursue another STEM course at follow up when compared to the students from the STEAM course. However, when comparing percentages at follow up by gender, more female students $(10 \%)$ from the STEAM course pursued STEM at follow-up than male students $(6.7 \%)$, while more male students $(17.9 \%)$ from the traditional STEM course pursued another STEM course than female students (14.3\%).

\section{Discussion}

Research shows that only five percent of associate degrees in community colleges across the country each year are earned in STEM fields (Packard, Gagnon, LaBelle, Jeffers, \& Lynn, 2011). This statistic is very significant as more than half of students today use community college as their initial introduction to higher education (Packard et al, 2011; St. Rose \& Hill, 2013). We researched the effect of introducing the arts into a STEM course in order to encourage more women to take STEM courses at a community college. The research purpose was to explore whether offering a STEAM class in a community college would encourage more women to pursue STEM subjects and whether having a female instructor as a role model would influence more women to consider pursuing STEM subjects.

\section{H1 Hypothesis}

The $\mathrm{H}_{1}$ hypothesis was satisfied: in the STEAM course, at the pre-test level, women were more interested than men in pursuing STEM. Perhaps the title of the course, "Chemistry with the Arts," piqued the interest of women taking the course. As explained earlier, women interested in STEM may have been drawn to the arts component in this STEM course description more so than men.

\section{H2 Hypothesis}

The $\mathrm{H}_{2}$ hypothesis was also satisfied: at the post-test level, in the STEAM course, while the overall mean for women and men decreased, female students tended 
to stay interested in the subject; they remained significantly more interested in the pursuit of STEM at the end than men in the same course.

The STEM course without the arts was a traditional chemistry class taught by the same female instructor. At the baseline pre-test there were no significant differences between male and female responses, but after the course, post-test responses showed that women in the traditional STEM course were more interested in the pursuit of STEM than men in the same course. This result was perhaps due to the female instructor who served as a role model for her female students.

\section{H3 Hypothesis}

In the follow up study using registration data for participants who attended the STEAM course in our study, a higher percentage of female students in comparison to male students took STEM courses over the next two semesters. This would indicate that STEM with the arts has a positive effect on female students pursuing STEM courses.

On the other hand, in the traditional STEM (without the arts) class, more men tended to take STEM courses in the next two semesters than women, possibly because this course was taught in the traditional manner, despite having a female instructor. Therefore, these results were in line with previous research (see Figure 1).

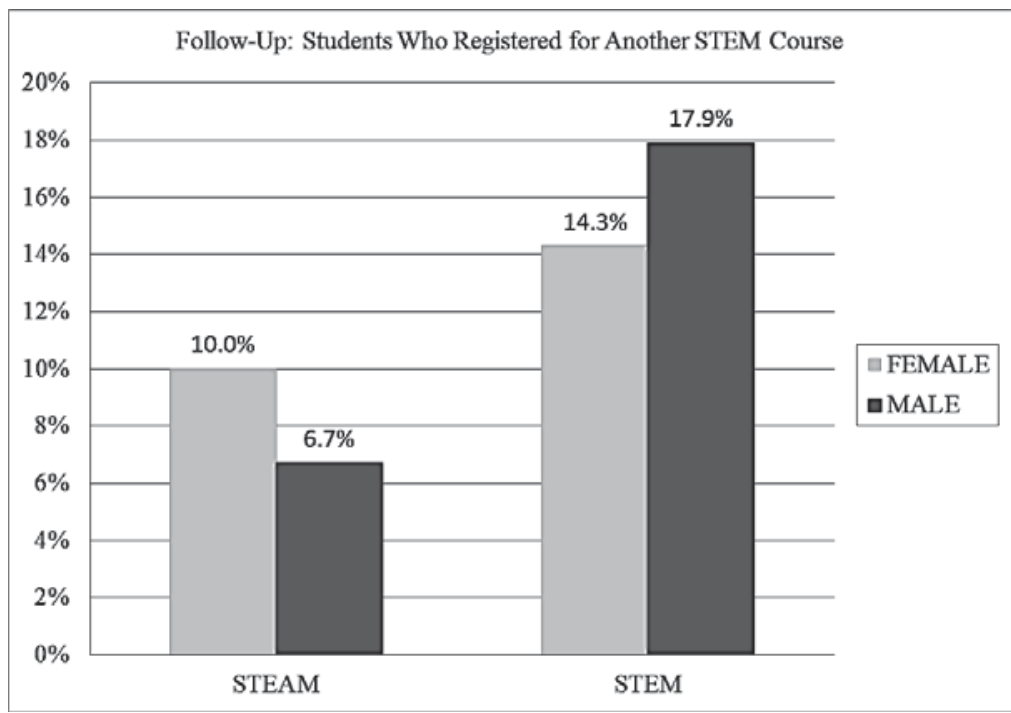

Figure 1. A larger percentage of female students from the STEAM course than from the traditional STEM course enrolled in another STEM course after the study ended.

\section{Limitations}

Since this research was conducted as a pilot study, there were a relatively small number of participants who were all students at one urban community college located in the northeastern U.S. They were not from a diverse set of two- and four-year colleges and universities. Additionally, for reasons unknown to the researchers, some 
subjects did not show up to class on the days that the post-test survey was distributed; participants dropping out can result in biased conclusions. However, the researchers believe that had there been a greater number of participants and lower participant mortality, there might have been even stronger positive results. In order to increase validity and reliability of the results, qualitative data such as interviews and openended questions collected from the students would have been more beneficial. Since a female professor was used in both conditions of the study, the researchers could not compare the results with data from students who had male professors. All of these factors should be considered when evaluating the results.

\section{Implications for Practice}

Based on our research results, revamping the curriculum starting from grades $\mathrm{K}$ through 12, continuing in undergraduate schools, and eventually in graduate schools, is necessary to really make changes in perception of one's ability and success in STEM, specifically for women. It is central to include the arts in STEM education and to encourage female students in the early grades. However, even changes at the 2-year and 4-year collegiate level can have an impact!

If educators start teaching female students about STEM/STEAM subjects at earlier ages and expose female students to more supportive female role models, it may be possible to increase STEM/STEAM-educated faculty in post-secondary institutions so that more female students enter STEM careers.

\section{Implications for Future Research}

This study needs to be expanded with a larger sample size and replicated at other community and four-year colleges and universities in different regions of the United States. Comparing the effects of pedagogical approaches of female STEAM professors to those of male STEAM professors on students' pursuit of STEM subjects at community and four-year colleges and universities should be studied. Various interdisciplinary courses that compare STEM learning with the arts (STEAM) to STEM learning without the arts should also be explored to see their effect on attrition rates and impact on women pursuing a STEM degree.

\section{Acknowledgements}

The authors are grateful to both Tirandai Hemraj-Benny and Jennifer Sokolow for their help and support.

\section{References}

Abbott, E., \& Breckinridge, S. P. (1906). Employment of women in industries: Twelfth census statistics. Journal of Political Economy, 14(1), 14-40. Retrieved from https://www.journals.uchicago.edu/doi/ pdfplus/10.1086/251185
American Bar Association (2017). A current glance at women in the law. Chicago: American Bar Association Commission on Women in the Profession. Retrieved from https://www.americanbar.org/content/d am/aba/marketing/women/current_glan ce_statistics_january2017.authcheckda m.pdf 
Ball, P. (2004). The molecular sculpture project HYLE. International Journal for Philosophy of Chemistry, 10 (2), 185-188.

Beede, D. N., Julian, T. A., Langdon, D., McKittrick, G., Khan, B., \& Doms, M. E. (2011). Women in STEM: A gender gap to innovation. Retrieved from http://www.esa.doc.gov/sites/default/files /womeninstemagaptoinnovation8311.pdf

Bettinger, E. (2010). To be or not to be: Major choices in budding scientists. In C. Clotfelter (Ed.), American universities in a global market (pp. 69-98). Chicago: University of Chicago Press. Retrieved from

http://www.nber.org/chapters/c11593

Bergen, B. (2016). U.S. medical school firsttime applicants by sex, 2006-2016 (p. 7). Association of American Medical Colleges. Retrieved from https://aamcblack.global.ssl.fastly.net/production/med ia/filer_public/78/3e/783e28cc-4bbf-4faba23a-

21f990cd2683/20161006_applicant_and_m atriculant_data_tables.pdf

Boy, G. A. (2013, August). From STEM to STEAM: Toward a human-centered education, creativity \& learning thinking. In Proceedings of the 31st European Conference on Cognitive Ergonomics (p. 3). ACM. Retrieved from https://ntrs.nasa.gov/archive/nasa/casi.ntr s.nasa.gov/20130011666.pdf

Caper, R. (1996). Play, experimentation and creativity. International Journal of Psycho-Analysis. 77, 859-869.

Catterall, J. S. (2002). The arts and the transfer of learning. In R. J. Deasy (Ed.), Critical links: Learning in the arts and student academic and social development. Washington, DC: Arts Education Partnership.
Chen, X. (2013). STEM attrition: College students' paths into and out of STEM fields (NCES 2014-001). Washington, DC: U.S. Department of Education, National Center for Education Statistics. Retrieved

from http://files.eric.ed.gov/fulltext/ED54 4470.pdf

Clynes, T. (2016). How to raise a genius: Lessons from a 45-year study of supersmart children. Nature, 537, 152-155. https://doi.org/10.1038/537152a

Costantino, T. (2017). STEAM by another name: Transdisciplinary practice in art and design education. Arts Education Policy Review, 119(2), 100106. doi: 10.1080/10632913.2017.1292973

Dail, W. (2013). On cultural polymathy: How visual thinking, culture, and community create a platform for progress. The STEAM Journal. 1(1). Retrieved from http://scholarship.claremont.edu/steam/vo 11/iss $1 / 7$

Goldberg Dey, J., \& Hill, C. (2007). Behind the pay gap. Washington: American Association of University Women Educational Foundation. Retrieved from

https://www.aauw.org/files/2013/02/Be hind-the-Pay-Gap.pdf

Graduate Management Admission Council. (2015). Women and graduate management education. (2015 Data-to-Go). Retrieved from https://www.gmac.com/ /media/Files/g mac/Research/diversityenrollment/gmac-2015-dtg-gme-andwomen-web-release.pdf 
Helmenstine, A. M. (2018, December 24). What is the importance of chemistry? ThoughtCo. Retrieved from https://www.thoughtco.com/what-isthe-importance-of-chemistry-604143

Herrmann, S. D., Adelman, R. M., Bodford, J. E., Graudejus, O., Okun, M. A., \& Kwan, V. S. (2016). The effects of a female role model on academic performance and persistence of women in STEM courses. Basic and Applied Social Psychology, 38, 258-268.

Hill, C., Corbett, C., \& St. Rose, A. (2010). Why so few? Women in science, technology, engineering, and mathematics. Washington: American Association of University Women. Retrieved from https://www.aauw.org/files/2013/02/W hy-So-Few-Women-in-ScienceTechnology-Engineering-andMathematics.pdf

Huston, A. C. (1983). Sex typing. In P.H. Mussen \& E. M. Hetherington (Eds.), Handbook of child psychology (4th ed., vol. 4, pp. 387-467). New York, NY: Wiley.

Institute of Physics. (2013). Closing doors: Exploring gender and subject choice in schools. London, England. Retrieved from

http://www.iop.org/publications/iop/20 13/file_62083.pdf

Karimi, S., Hemraj-Benny, T., \& Bojin, M. (2015). Chemistry and the arts laboratory manual (3rd ed.). Minneapolis, Minnesota: Bluedoor Publishing.

Kezar, A., \& Elrod, S. (2012). Facilitating interdisciplinary learning: Lessons from project kaleidoscope. Change: The Magazine of Higher Learning, 44(1), 16-25. https://doi.org/10.1080/00091383.2012.63 5999
Lackland, A. C., \& De Lisi, R. (2001). Students' choices of college majors that are gender traditional and nontraditional. Journal of College Student Development, 42(1), 39-47.

Land, M. H. (2013). Full STEAM ahead: The benefits of integrating the arts into STEM. Procedia Computer Science, 20, 547 552.

https://doi.org/10.1016/j.procs.2013.09.3 17

Langdon, D., McKittrick, G., Beede, D., Khan, B., \& Doms, M. (2011, July). STEM: Good jobs now and for the future. (Issue Brief No 03-11). Washington DC US Department of Commerce.

Madden, M. E., Baxter, M., Beauchamp, H., Bouchard, K., Habermas, D., Huff, M., ... \& Plague, G. (2013). Rethinking STEM education: An interdisciplinary STEAM curriculum. Procedia Computer Science, 20, 541-546.

doi: 10.1016/j.procs.2013.09.316

Margolis, J., \& Fisher, A. (2003). Unlocking the clubhouse: Women in computing. MIT Press.

Marra, R. M., Peterson, K., \& Britsch, B. (2008). Collaboration as a means to building capacity: Results and future directions of the National Girls Collaborative Project. Journal of Women and Minorities in Science and Engineering, 14, 119-140.

https://doi.org/10.1615/JWomenMinorS cienEng.v14.i2.10

Marx, D. M., Brown, J. L., \& Steele, C. M. (1999). Allport's legacy and the situational press of stereotypes. Journal of Social Issues, 55, 491-502. https://doi.org/10.1111/0022-4537.00129 
Marx, D. M., \& Roman, J. S. (2002). Female role models: Protecting women's math test performance. Personality and Social Psychology Bulletin, 28, 1183-1193. https://doi.org/10.1177/014616720228120 04

McClarty, K. L. (2015). Life in the fast lane: Effects of early grade acceleration on high school and college outcomes. Gifted Child Quarterly, 59, 3-13. https://doi.org/10.1177/001698621455959 5

Moran, G. (November 9, 2015). Women now make up $40 \%$ of students at top MBA programs. Fortune. Retrieved from http://fortune.com/2015/11/09/womenmba-40-percent/

Morgan, C. L., Isaac, J., \& Sansone, C. (2001). The role of interest in understanding the career choices of female and male college students. Sex Roles, 44, 295-320.

https://doi.org/10.1023/A:1010929600004

National Center for Education Statistics. (2017). Fast facts: Degrees conferred by race and sex. Retrieved from

https://nces.ed.gov/fastfacts/display.asp?i $\mathrm{d}=72$

National Girls Collaborative Project. (2016, August). The state of girls and women in STEM. Retrieved from https://ngcproject.org/statistics

National Science Board. (2016). Science and engineering indicators 2016 (NSB2016-1). Arlington, VA: National Science Foundation.

National Science Foundation. (2016) Doctoral degrees awarded to women, by field: 2004-14 [Table 7-2]. Retrieved from

https://www.nsf.gov/statistics/2017/nsf173 10/static/data/tab7-2.pdf

InSight: A Journal of Scholarly Teaching
Noonan, R. Office of the Chief Economist, Economics and Statistics Administration, U.S. Department of Commerce. (2017). Women in STEM: 2017 Update (ESA Issue Brief \#06-17). Retrieved from https://www.esa.gov/reports/womenstem-2017-update

O'Farrell, B. (2015). American women: Looking back, moving ahead - the 50th anniversary of the President's Commission on the Status of Women report. Washington, DC: U.S. Department of Labor, Women's Bureau. Retrieved from https://www.dol.gov/wb/resources/lookin g_back_moving_ahead.pdf

Packard, B. W. L., Gagnon, J. L., LaBelle, O., Jeffers, K., \& Lynn, E. (2011). Women's experiences in the STEM community college transfer pathway. Journal of Women and Minorities in Science and Engineering, 17, 129-147. Retrieved from http://nassites.org/communitycollegessummit/files/ 2011/11/Packard_et_al_JWMSE_2011.pdf

Root-Bernstein, R. S. (2003). The art of innovation: Polymaths and the universality of the creative process. In L. Shavanina (Ed.), International handbook of innovation, (pp. 267-278). Amsterdam: Elsevier.

Root-Bernstein R., Allen L., Beach L., Bhadula R., Fast J., Hosey C., ...Weinlander S. (2008). Arts foster scientific success: Avocations of Nobel National Academy, Royal Society, and Sigma XI members. Journal of Psychology of Science and Technology, 1(2), 51-63.

Shneiderman, B. (2003). Leonardo's laptop: Human needs and the new computing technologies. Cambridge, MA: The MIT Press. 
Sochacka, N. W., Guyotte, K. W., \& Walther, J. (2016). Learning together: A collaborative autoethnographic exploration of STEAM (STEM+ the Arts) education. Journal of Engineering Education, 105(1), 15-42. doi:10.1002/jee.20112

St. Rose, A., \& Hill, C. (2013). Women in community colleges: Access to success. Washington, DC: American Association of University Women. Retrieved from https://www.aauw.org/files/2013/05/wo men-in-community-colleges.pdf

Taylor, B. (2016). Evaluating the benefit of the maker movement in K-12 STEM education. Electronic International Journal of Education, Arts, and Science (EIJEAS), 2.

U.S. Bureau of Labor Statistics. (2015). Women in the labor force: A databook (Report 1059). Washington, DC: U.S. Department of Labor. Retrieved from

https://www.bls.gov/opub/reports/wo mens-databook/archive/women-in-thelabor-force-a-databook-2015.pdf
U.S. president's commission on the status of women (1963). American women: Report of the president's commission on the status of women. Retrieved from https://www.dol.gov/wb/American\%20 Women\%20Report.pdf

You, H. S. (2017). Why teach science with an interdisciplinary approach: History, trends, and conceptual frameworks. Journal of Education and Learning, 6(4), 66-77. doi:10.5539/jel.v6n4p66

Young, D. M., Rudman, L. A., Buettner, H. M., \& McLean, M. C. (2013). The influence of female role models on women's implicit science cognitions. Psychology of Women Quarterly, 37, 283-292. https://doi.org/10.1177/036168431348210 9

Clara Wajngurt earned her PhD in Mathematics from The City University of New York (CUNY). She is a Professor of Mathematics and Computer Science at Queensborough Community College for many years. In addition to her research in number theory, she is working on research in disability education, workplace bullying prevention, and STEM learning and curriculum. She is especially interested in helping women advance in their educational interests and attain leadership roles in society.

Pessy J. Sloan received her PhD in clinical and school psychology from Hofstra University. She is an assistant professor in the Education Department of Daemen College. She has many years of experience as a clinician, school psychologist, and researcher. Her current areas of research focus on gifted and high achieving students, women, and STEM. 